\title{
Quantitative Map Literacy: A Cross between Map Literacy and Quantitative Literacy
}

\author{
Ming Xie \\ University of South Florida, mingxie@mail.usf.edu \\ H. L. Vacher \\ University of South Florida, vacher@usf.edu \\ Steven Reader \\ University of South Florida, sreader@usf.edu \\ Elizabeth Walton \\ University of South Florida, emwalton@usf.edu
}

Follow this and additional works at: https://digitalcommons.usf.edu/numeracy

Part of the Earth Sciences Commons, Geographic Information Sciences Commons, Science and Mathematics Education Commons, and the Secondary Education Commons

\section{Recommended Citation}

Xie, Ming, H. L. Vacher, Steven Reader, and Elizabeth Walton. "Quantitative Map Literacy: A Cross between Map Literacy and Quantitative Literacy." Numeracy 11, Iss. 1 (2018): Article 4. DOI: https://doi.org/

10.5038/1936-4660.11.1.4 


\title{
Quantitative Map Literacy: A Cross between Map Literacy and Quantitative Literacy
}

\begin{abstract}
We define quantitative map literacy (QML), a cross between map literacy and quantitative literacy (QL), as the concepts and skills required to accurately read, use, interpret, and understand the quantitative information embedded in a geospatial representation of data on a geographic background. Long used as tools in technical geographic fields, maps are now a common vehicle for communicating quantitative information to the public. As such, QML has potential to stand alongside health numeracy and financial literacy as an identifiable subdomain of transdisciplinary QL.

What concepts and skills are crucial for QML? The obvious answer is, "It depends on the type of map." Therefore, our first task, and the subject of this paper, is to develop a framework to think and talk about the panoply of maps in a way that permits us to consider the range and distribution of QML content. We use an equilateral triangular plot to conceptualize maps in terms of locational information (L), thematic information ( $T$ ), and generalization-distortion (G-D), and parameterize the plot with an L/T ratio (horizontal; reflecting the historical practice of cartographers to distinguish locational-reference maps from thematic maps) and G-D levels increasing from base to apex. We show positions for a wide variety of maps (e.g., topographic maps, weather maps, engineering-survey plots, subway maps, maps of air routes, a cartoon map of Orlando for tourists, driving-time maps, county-wide population maps, countywide multivariable population and income maps, world political map, land use maps, and cartograms). The analysis of how these maps vary across the triangle allows us to proceed with an examination of how QML varies across the panoply of maps.
\end{abstract}

\section{Keywords}

Map, Map Literacy, Quantitative Literacy, Quantitative Map Literacy, Thematic Maps, Reference Maps

\section{Creative Commons License}

This work is licensed under a Creative Commons Attribution-Noncommercial 4.0 License

\section{Cover Page Footnote}

Ming Xie is a Ph. D. candidate in School of Geosciences, University of South Florida - Tampa. He obtained his Bachelor Degree in Geography from Nanjing University, China, and Masters Degree in Coastal Geology from USF. His dissertation research is in the new cross-disciplinary field of quantitative map literacy.

Len Vacher, Steven Reader, and Elizabeth Walton are Professor, Associate Professor and Instructor, respectively, in the School of Geosciences (SGS) at the USF - Tampa. Vacher is a hydrogeologist, now specializing in QL across the geology curriculum. Reader is a geographer specializing in GIScience and spatial statistics for social science applications. Walton is a geographer specializing in geographic information systems and science technologies and remote sensing, with applications to the ecology of turtle populations. We believe this paper marks the first scholarly publication resulting directly from the merger of the Departments of Geology, Geography, and Environmental Science and Policy to form USF's SGS. 


\section{Introduction}

This paper is the first in a series in which we discuss the concept of quantitative map literacy and how it applies to quantitative literacy (QL) in general. We define quantitative map literacy as the knowledge (concepts, skills and facts) required to accurately read, use, interpret, and understand the quantitative information embedded in a geospatial representation of data on a geographic background. The advent and increasingly widespread use of desktop geographical information systems (GIS) and other mapping software over the past 20 years has revolutionized and democratized the production of maps to the point where they are now commonplace in newspapers and periodicals. Maps greatly impact the overall literacy of our citizenry on major issues. As such, we believe a systematic consideration of quantitative map literacy is both significant and timely. Of course, there is a long history of studying the communication and understanding of quantitative information in graphics (e.g., Tufte 1992, 2001), but, as "graphics" that represent geographic or geospatial information, maps have specific attributes that cry out for separate study. Not surprisingly, quantitative reasoning with maps has started to draw the attention of others in the QL community (e.g., Jungck 2012; Perez et al. 2015).

A foundational - and self-evident - concept of this series of articles is that the constitution of quantitative map literacy varies with the characteristics of a map. These characteristics are linked to map purpose. The characteristics and purposes of maps lead to a diversity of map types. As we began our research into quantitative map literacy, we became aware that, to the best of our knowledge, a systematic map classification scheme for map types, on which we might base our research, is lacking. Cartographers have certainly defined various types of maps, but generally they fall into broad categories that fail to accommodate the nuances of different map characteristics that we think are significant. Accordingly, our goal in this first paper is to produce a general framework within which key map characteristics can be used as the basis for discussion in subsequent papers of how quantitative map literacy varies with the balance and level of these key characteristics as we see them. We wish to emphasize that we are not proposing a new map classification per se, but rather a system for thinking about quantitative information communicated by maps; more specifically, we envisage maps positioned within a bi-directional continuum based on three characteristics (locational information, thematic information, and generalization/distortion) that, we believe, will help us think about quantitative map literacy. 


\section{Background}

In cartography, map types are generally defined and named based on purpose and theme. Some example quotations illustrating these definitions are (italics added):

- "Another name commonly applied to the general purpose map is reference map" (Robinson 1975). "Such maps customarily display objects (both natural and man-made) from the geographic environment. The emphasis is on location, and the purpose is to show a variety of features of the world or a portion of it" (quotation from Robinson and Petchenik 1976, as found in Dent et al. 2009, 6).

- "Maps that show the shape and elevation of terrain are generally called topographic maps" (Campbell 1993, 9).

- "Cadastral maps show how land is divided into real property, and sometimes the kinds of built improvements" (Harvey 2008, 13).

- "Thematic maps (or statistical maps) are used to emphasize the spatial pattern of one or more geographic attributes (or variables), such as population density, family income, and daily temperature maximums" (Slocum et al. 2009). The thematic map's "main objective is specifically to communicate geographical concepts such as the distribution of densities, relative magnitudes, gradients, spatial relationships, movements, and all the myriad interrelationships and aspects among the distributional characteristics of the earth's phenomena" (Robinson and Sale 1953, 10-11).

- "The choropleth map is a common map type for mapping data collected in enumeration units. Each unit, such as a county, state, country, province, is shaded according to a variable or attribute, such as population density" (Dent et al. 2009, 8). "Choropleth mapping is performed by mapping spatial data that are constrained to lie within a bona fide administrative unit. The administrative unit may be based on political jurisdictions such as cities, counties, states, countries, school districts, emergency response districts, and tax zones, etc." (Jensen and Jensen 2013, 306).

- "Cartograms, both contiguous and non-contiguous, show quantitative difference by altering the size of the geographic units according to the relative proportion of the geographic unit's property" (Harvey 2008, 213). "Cartograms are created by substituting a different standard of measurement (time or cost, for example) for the distance measurements customarily used. When this is done, sizes, shapes and distances as we normally think of them are modified or distorted" (Campbell 1993). ${ }^{1}$

According to the prominent cartographer B.D. Dent, maps can first be classified according to the media used (Dent et al. 2009). He identifies mental maps, tangible maps, and virtual maps (Fig. 1). Mental maps are "developed in our minds over time by the accumulation of many sensory inputs, including tangible or virtual maps" (Dent et al. 2009). Within the realm of maps produced on tangible or virtual media (our focus), two major types of maps are identified: general purpose (reference maps) and thematic maps (Dent et al. 2009). Reference maps focus on displaying location information about geographic features, i.e.,

${ }^{1}$ For examples, see https://en.wikipedia.org/wiki/Cartogram (last accessed Nov 25, 2017) 
geographic features that are tangibly located on Earth (such as rivers, roads, and political boundaries). In contrast, thematic maps are made to display attribute information or data, i.e., quantitative or categorical data that cannot be directly observed on Earth (such as population, income, house prices, electoral voting, and the like; i.e., the types of maps increasingly found in the print and online media through the democratization of map production enabled by GIS).

We perceive quantitative map literacy as part of the more general topic of map literacy. Pertinent to our study in that regard is the realization that previous work on map literacy has either been sufficiently general that map type was not considered, or studies of map literacy have been (narrowly) focused on one broad type of map or another. For example, the

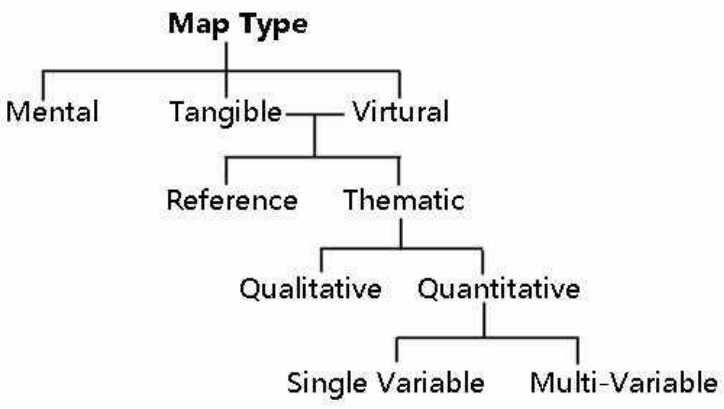

Figure 1. A taxonomy of map types (redrawn from Dent et al. 2009).

early works of Olson (1976), Board (1978) and Morrison (1978) summarized map reading tasks and skills, such as "navigation" or "measurement," which were clearly focused on reference maps. Building on these works, Clarke (2003) proposed the term "functional map literacy" as the "ability to understand and use maps in daily life, for work, and in the community" (717). He developed a hierarchy of map-reading abilities from the simple task of symbol recognition to the complex task of understanding the meaning of spatial phenomena. Because his work generally builds upon the early works of Olson (1976), Board (1978) and Morrison (1978), those map literacy skills are focused mainly on reference maps. Evaluation scales and instruments for assessment of map literacy have also been developed for reference maps, such as one for assessment based on a 2-D shaded relief map (Lee and Bednarz 2012) and evaluation scales for map literacy based on topographic maps (Koc and Demir 2014; Rautenbach et al. 2017).

Regarding map literacy for thematic maps, Kulhavy et al. (1992) categorize the basic components of thematic map reading as identifying, describing, counting, and relating thematic information. Many cartographers and GIS researchers (Rieger 1999; Bayran and Ibrahim 2005; Lloyd and Bunch 2005, 2008) have explored the relationship between thematic map literacy and demographic types of users (e.g., gender, education, income). Although not using the exact words "map literacy," these studies used map-based assessment instruments to investigate users' understanding of thematic maps by testing whether they could correctly obtain information, and then compared results, including reaction time and accuracy, across individual differences. 
Classification of maps as either "reference" or "thematic," however, generally reflects their primary purpose, and so what becomes obscured through such a classification is that maps generally contain a mixture of locational information and thematic information. We argue that the types and balances of quantitative concepts and skills vary across this mixture and, therefore, a more nuanced organizational framework that recognizes a continuum is needed. Also, and just as importantly, we point out that maps occupying similar locations along this continuum between locational and thematic information endpoints may vary substantially in terms of accuracy and precision. This variation in accuracy and precision is caused by effects of geographic scale, map projection, locational and thematic data generalization, and locational and thematic data distortion. Such concepts also impact the types and balances of quantitative concepts and skills required and, therefore, we propose that a second dimension to our organizational framework for maps, for the purpose of quantitative map literacy, be added to represent the amount of generalization and/or distortion present in the map product.

Given these two dimensions - (1) a ratio of locational information to thematic information, and (2) a level of generalization and/or distortion - we propose to adopt a triangular, or ternary, plot to visualize our organizational framework. Similar plots are commonly found in fields such as physical chemistry, petrology, mineralogy, pedology/edaphology, and metallurgy, among other natural and applied sciences (Pettijohn, 1957; Derringh, 1998), where the plots are used to graph the mixtures of three different components (or endmembers). Figure $2 \mathrm{a}$ shows a classic example of a triangular plot applied to sedimentary deposits (e.g., as in a beach or a river bar). The three endmembers are mud, sand, and gravel. Locations and boundaries within the triangle reflect, in this case, the two dimensions of sand-to-mud ratio and percent gravel.

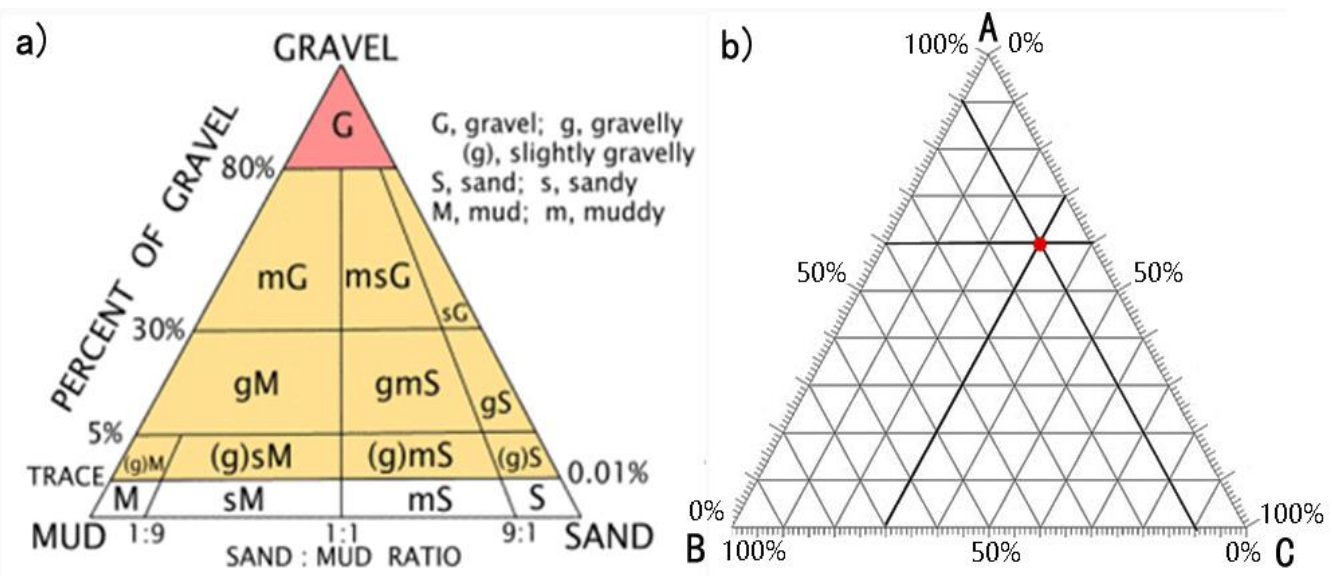

Figure 2. Examples of triangular plots: (a) Folk's classification system of sediment types (Folk 1974) (from Poppe et al. 2005); (b) A typical triangular plot with edge-parallel grid lines. 
By way of explanation, every location inside a standard triangular plot represents the percentage composition of the three endmembers shown at the vertices. The featured dot in Figure $2 \mathrm{~b}$, for example, has the composition $60 \% \mathrm{~A}$, $10 \% \mathrm{~B}$, and $30 \% \mathrm{C}$. The three legs of the triangle are each a binary mixture; for example, points along the $\mathrm{BC}$ leg are mixtures of $\mathrm{B}$ and $\mathrm{C}$. The grid lines are labeled $0 \%$ to $100 \%$ along each of the legs of the triangle from one endmember to the other, generally in an overall clockwise direction. Thus along the $\mathrm{BC}$ leg, the labels go from 0 at $\mathrm{C}$ to 100 at $\mathrm{B}$, meaning that the percentage of endmember $\mathrm{B}$ in the binary mix increases from $0 \%$ at $\mathrm{C}$ to $100 \%$ at $\mathrm{B}$. The three legs each represent the $0 \%$ contour for the percentage of the opposite-vertex endmember in the three-way mix. Each of the other grid lines is a contour of the percentage of the opposite-vertex endmember; for example, the three highlighted gridlines in Figure $2 \mathrm{~b}$ are the (horizontal) $\mathrm{A}=60 \%$ contour, the (upper-left to lower-right) $\mathrm{B}=10 \%$ contour, and the (lower-left to upper-right) $\mathrm{C}=30 \%$ contour. (For more details, see Wainer 1997 and Vacher 2005).

The contour lines discussed above can be termed iso-percentage lines. In addition to these contour lines, isoratio contours (Fig. 3) can be useful. A line from one vertex to the opposite leg (from A to $\mathrm{BC}$ in Figure 3) represents a constant ratio of the percentages of the two endmembers of the opposite leg (i.e., the line is a contour of $\mathrm{B}: \mathrm{C})$. In the case of the highlighted iso-ratio contour shown in

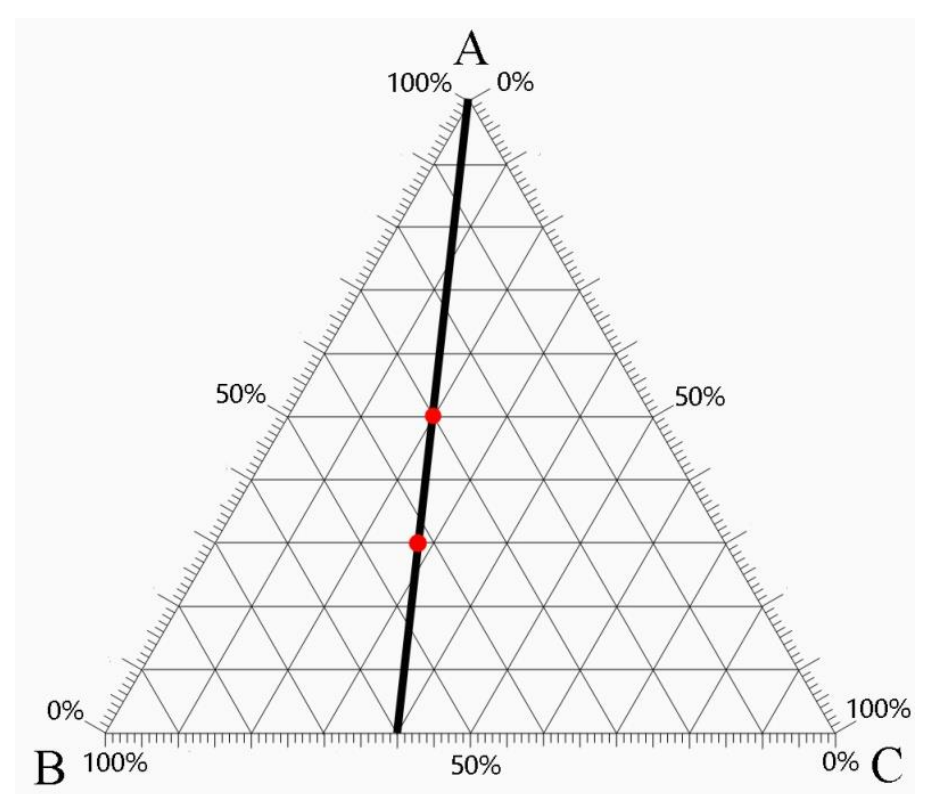

Figure 3. An iso-ratio contour in a triangular plot $(\mathrm{B}: \mathrm{C}=3: 2)$.

Figure 3, the $\mathrm{B}: \mathrm{C}$ ratio is $60 \%$ to $40 \%$, or $3: 2$, which can be read on the scale along $\mathrm{BC}$. The same ratio applies at the two featured dots on the same figure. Thus the composition at the upper dot is $50 \% \mathrm{~A}, 30 \% \mathrm{~B}$, and $20 \% \mathrm{C}$, and the composition at the lower dot is $30 \% \mathrm{~A}, 42 \% \mathrm{~B}$, and $28 \% \mathrm{C}$.

These two types of contours provide two schemata for dividing a triangular plot into regions. Iso-percentage lines, which run parallel to an edge of the triangle (Fig. 4a), emphasize the percentage of a single endmember; iso-ratio lines, which extend from a vertex to an opposite edge (Fig. 4b), emphasize the 
ratio of two endmembers. In the case of Figure 2a, both these types of line were used to demarcate regions, which then produced a classic typology of sedimentary rocks (Folk 1974).
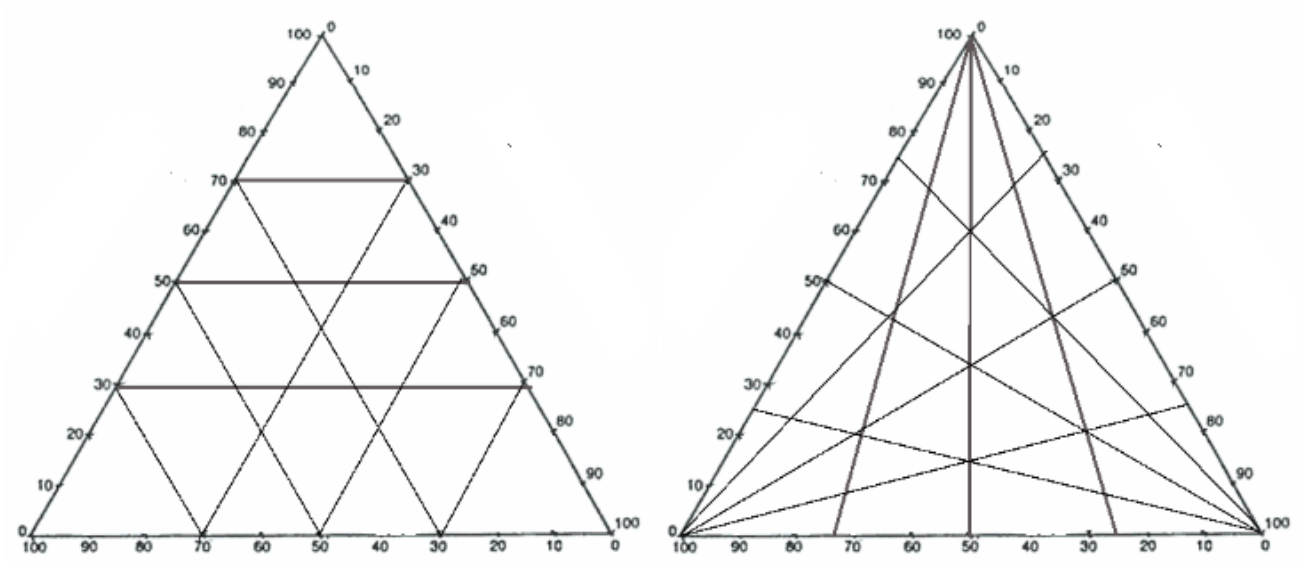

Figure 4. Two ways of dividing triangular plots corresponding to the two different types of contours: isopercentage lines (left); iso-ratio lines (right).

\section{Proposed Triangular Plot for Maps}

In order to design a triangular plot for maps, we propose three conceptual endmembers: "locational information," "thematic information," and "generalization and/or distortion" (see Fig. 5). Similar to the Folk (1974) plot (Fig. 2a), we also propose two dimensions (hereafter referred to as parameters).

The first is the ratio between locational information and thematic information (the "locational-tothematic" or "L/T-ratio parameter"), and the second is the level of generalization and/or distortion (the "generalization-distortion" or "G-D parameter"). Any map can be plotted within our triangle based on an assessment of these two parameters, with placement using the iso-ratio lines for the L/T-ratio parameter and the iso-level lines for the G-D parameter. The assessment proceeds by first considering the L/T-ratio and

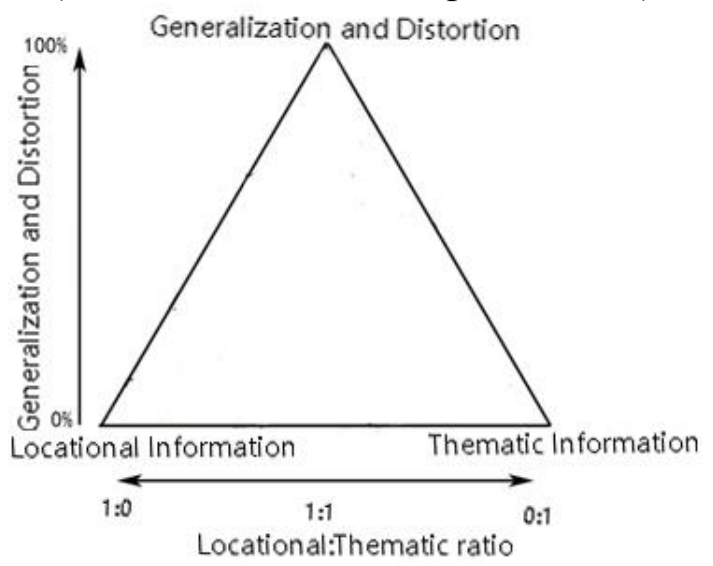

Figure 5. Proposed triangular plot for thinking about maps. then, subsequently, the G-D level.

We are proposing this framework for maps only because it meets our needs 
for consideration of quantitative map literacy. We have not formally considered the more general usefulness of our scheme within cartography, although we would certainly welcome scholarly consideration of that by others. In this regard, and unlike the Folk (1974) plot of Figure 2a, we note that we are not proposing to identify and label regions of our triangle for specific map types based on iso-ratio and iso-level line boundaries, although we do recognize that it would be an interesting (and, no doubt, provocative) exercise for future work. For the purpose of thinking about quantitative map literacy, we are more interested in examining how maps and attendant QL skills vary as one moves across the triangle defined by our two parameters (and three endmembers).

We also do not intend to be dogmatically prescriptive as to where any particular map may be placed in the triangle. We anticipate that different individuals would place maps in different locations, perhaps reflecting their own intentions and use of map products based upon their own (or cultural) biases and context. We do suggest, however, where we believe some maps types may lie in the triangle in the subsequent section to this paper, but even as authors we had slightly different viewpoints as we worked through our examples. ${ }^{2}$

Regarding the L/T-ratio parameter, the key aspect to consider is the purpose of the map, and that issue can be complicated. The question of map purpose involves an interplay between the mapmaker's intended purpose for the map and the actual interpretation or purpose bestowed on it by the user. Because thematic maps actively communicate a message, the intention (of the mapmaker) and the interpretation (by the user) are typically more congruent with regard to purpose (though not necessarily effectiveness). With locational maps, the intent of the mapmaker is to present message-free reference data which the user can put to many different purposes, including ones that the mapmaker may not have thought of (although, by the very nature of such maps, these purposes are largely constrained to involve the locational properties of the features presented).

Tufte $(1992,2001)$ states that a graph should display meaningful information, and all other graphic features are "graph junk." For example, readers are probably familiar with historic exploration maps where presumed, but unexplored, lands or seas were often adorned with elaborate symbols such as serpents, dragons, and the like. Although in some cases such symbols were suggestive of what "themes" lay beyond (e.g., a buffalo in the American West) and therefore somewhat informative, in many cases they would qualify as "graph junk." Similarly, a modern thematic map could include a large amount of locational information in the form of geographic features, such as administrative boundaries, highways, river systems and so on, which provide reference, but which are not germane to the main theme (purpose) of the map. We may not consider such features as

\footnotetext{
${ }^{2}$ It is perhaps interesting to note that the authors hail from China, the UK, and the United States.
} 
"graph junk" necessarily, but the ratio of locational to thematic information would certainly be tilted towards the thematic. Our point, in other words, is that it is not the sheer quantity of raw information presented that is important (i.e., the "ink" in Tufte's vernacular) but rather the importance of that information to the map's purpose (the "meaning").

It is also important to note that the G-D level considers the generalization and distortion in both the locational information and the thematic information simultaneously. For locational data, generalization can take the form of simplified feature representation, feature selection, feature classification, and so on. Distortion of locational data derives from such processes as map projection and the deliberate offset of features to accommodate their display without conflicting with other map components. For thematic data, on the other hand, generalization may reflect more-reductionist data-classification schemes, such as aggregation of data to coarser geographic features, as in spatial hierarchies of political or administrative units, or simply coarser data classes. Distortion in thematic data may result from data simplification or the intentional choice of a certain thematic data-classification scheme over another. In this latter regard, it should be noted that distortion may be benign and simply result from well-intentioned processes such as accommodating coincident spatial features or simplifying data for easier interpretation (e.g., rounding numbers), or it may be quite intentional as in the case of the manipulation of a thematic data-classification scheme to influence the interpretation of the map (e.g., Monmonier 1996). Similarly, it should also be noted for the locational data case that the choice of map projection, though often benign or simply uninformed, is sometimes intentional. A good, historically familiar example would be the production in the United States of politically expedient (read propaganda) "Cold War" maps using the World Mercator projection - a projection which "conveniently" exaggerates the areal extent of high-latitude land countries (such as the "menacing" Soviet Union) and relatively diminishes the areal extent of lower-latitude countries such as the United States and countries that lie in the region of the equator.

In some cases, generalization and distortion are related. One example already mentioned is where thematic data may be generalized to different levels of (say) areal units (counties, states) and, yet, this generalization obviously changes the portrayal of locational data too. An even more-stark example would be the cartogram. In a cartogram, locational data are deliberately distorted so that some geometric attribute of the locational data is made directly proportional (thus sensitive) to the value of a thematic attribute (e.g., where the geographic areas of states directly reflect their numerical populations). In a cartogram, therefore, locational data are intentionally distorted to give a more-accurate (i.e., lessgeneralized) portrayal of the thematic attribute. An interesting question in this regard then becomes how would we assess the overall G-D parameter for a 
cartogram? We argue that this assessment needs to take place with the purpose of the map in mind. Since the main purpose of a cartogram is to better communicate the thematic attribute in a non-generalized way, the fact that we may greatly distort the locational data is comparatively less important. Consequently, in our view, the cartogram has a low level of generalization-distortion given the relative weighting of thematic vs. locational importance. We take this position despite how counter-intuitive it may seem at first sight (which, shall we say, was one of our own internal points for lively discussion during our analysis).

Given these observations, we propose that "assessment" of the level of the G$\mathrm{D}$ parameter use the following conceptual equation (a weighted average)

$$
Z=Z_{L} \cdot \frac{L}{L+T}+Z_{T} \cdot \frac{T}{L+T}
$$

where $Z$ is the "assessment" of overall generalization-distortion; $Z_{L}$ is the generalization-distortion "assessment" for the locational information; $Z_{T}$ is the generalization-distortion "assessment" for the thematic information; $L$ is the "assessment" of the importance of the locational information to the map's purpose; and $T$ is the "assessment" of the importance of the thematic information to the map's purpose. Determination of $Z$ thus depends on the prior assessments of $L$ and $T$ for the first parameter of our two-dimensional (two-parameter) scheme discussed above. Obviously we do not advocate strict quantitative evaluation of the variables in this equation (which is why we use the quotation marks for "assessment"). The equation is meant to be a conceptual model to have in mind as one thinks about the location of a given map in the triangular plot we are proposing. (Not surprisingly, perhaps, the equation itself was another locus of lively discussion).

\section{Maps across the Triangle}

As stated, maps can be located on the triangular plot by considering two parameters: the ratio of locational information to thematic information (the " $\mathrm{L} / \mathrm{T}$ ratio") and the level of map generalization and/or distortion (the "G-D level"). We contend that similar maps tend to be located within similar areas on the triangular plot. Moreover, the differences and connections between maps can be instructively discussed by examining trends across the triangular plot.

On the left side of the triangle, maps are generally focused on the provision of locational information. The maps portrayed in Figure 6 occupy an "iso-ratio wedge" of similar, relatively high, L/T ratios. However, as the map scale decreases (large-scale [small area of coverage] to small-scale [large area of coverage]), the maps move upwards within the wedge to reflect higher G-D levels of generalization-distortion. Note that although the maps in Figure 6 have similar 
$\mathrm{L} / \mathrm{T}$ ratios that reflect the map purpose, the two larger-scale maps (c, d) are located more to the right within the wedge. This shift reflects the fact that the thematic content, and importance, is greater in the larger-scale maps.
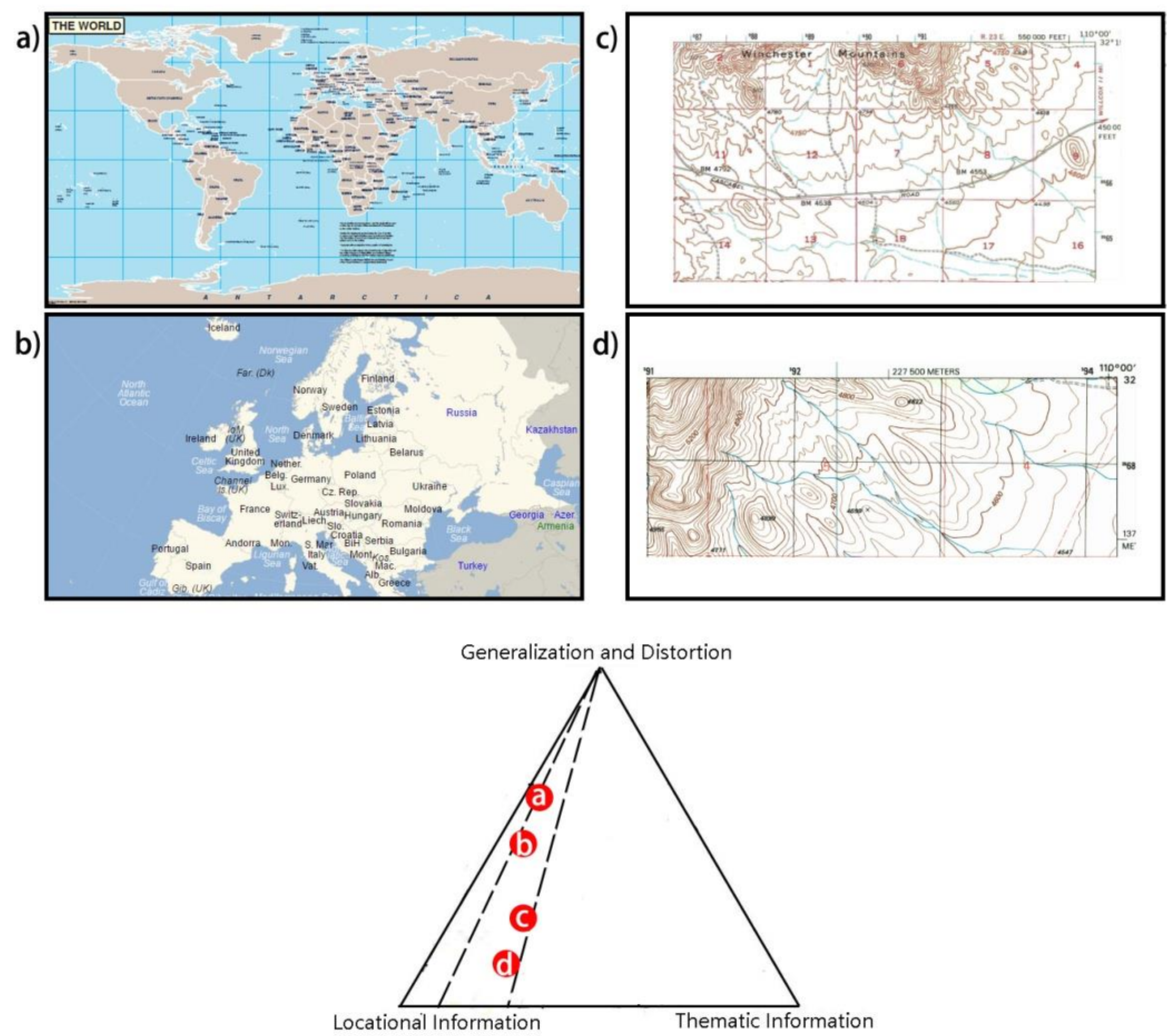

Figure 6. Examples of maps at different G-D levels in a high-L/T wedge of the map triangle: (a) World Map (United Nations 2010); (b) political map of Europe (Ssolbergj 2009); (c) 15×15 minute USGS Topographic Map of Dragoon, AZ. (U. S. Geological Survey 1958); and (d) 7.5×7.5 minute USGS Topographic Map of Steele Hills, AZ. (U. S. Geological Survey 1996).

Conversely, maps on the right side of the triangle (relatively low $\mathrm{L} / \mathrm{T}$ ratios) are generally focused on the communication of thematic information (Fig. 7). The amount of generalization and/or distortion in thematic maps is mostly driven by choices in how the data are represented (e.g., data classification). For example, the three maps in Figure 7 are made with the same data: the population of counties in the state of New York. The two choropleth maps (Figs. 7a and 7b) differ in the granularity of the classes: three classes in Figure 7a (high G-D), and seven classes in Figure $7 b$ (lower G-D). The map with seven classes obviously displays a less-reductionist representation of the thematic data. 
a)

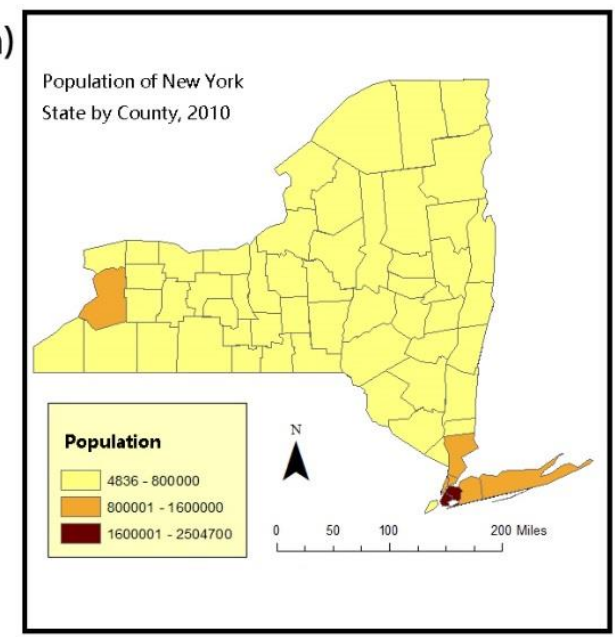

b)

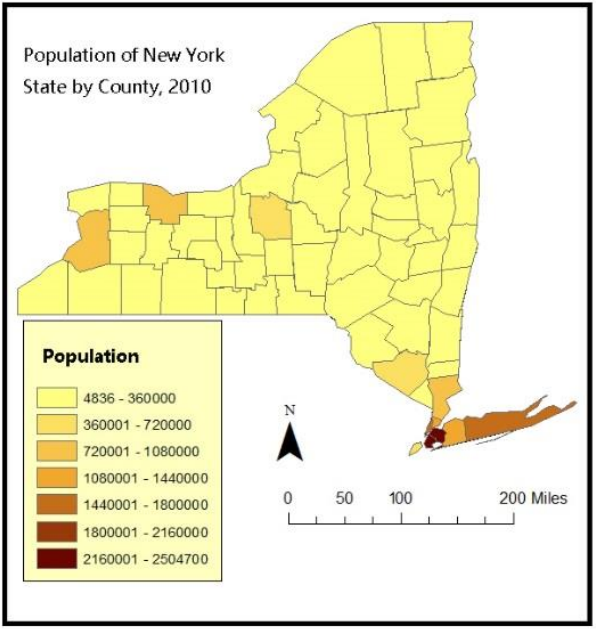

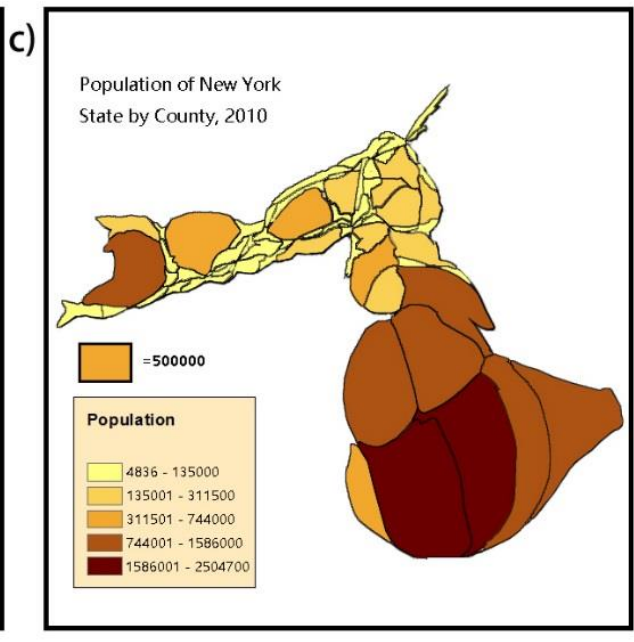

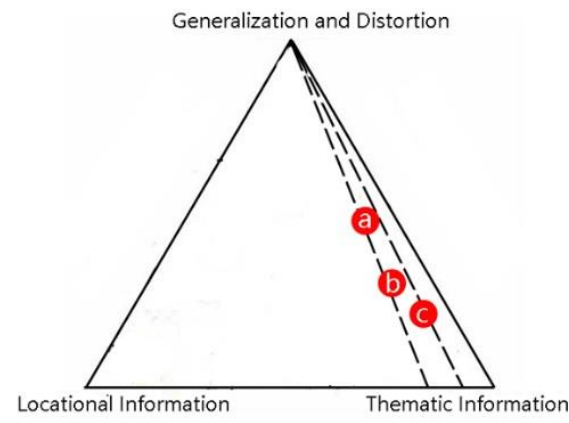

Figure 7. Examples of maps at different G-D levels in a low-L/T wedge of the map triangle: (a) Population of New York State by County, 2010 (three data classes); (b) Population of New York State by County, 2010 (seven data classes); (c) Population of New York State by County, 2010 (Cartogram). (Data source: United States Census Bureau. ${ }^{3}$

Figure $7 \mathrm{c}$, on the other hand, is a cartogram of the county population data, where the geometries of the geographic features (counties) are highly distorted so that their areas are proportional to the values of a specific "attribute" (the GIS term for the thematic data). Although the locational information is highly distorted, the representation of the thematic data is now a direct translation of the numeric value of the attribute so it is less generalized than the data representation of the choropleth maps of Figures $7 \mathrm{a}$ and $7 \mathrm{~b}$. Therefore, according to our conceptual equation, the cartogram is placed lower in the $\mathrm{L} / \mathrm{T}$ wedge because the distortion in the locational information has little weight for maps with a low $\mathrm{L} / \mathrm{T}$

${ }^{3}$ Accessed from: https://www.census.gov/mp/www/cat/decennial_census_2010/(Oct. 2017). 
ratio, and, as stated, there is minimal generalization of the thematic data. Note that although the maps in Figure 7 have similar $\mathrm{L} / \mathrm{T}$ ratios that reflect the map purpose, the choropleth maps do communicate the location of the thematic data in a more direct way, and so they place a little more to the left within the wedge. Meanwhile, in addition to its proportional representation of population by geographic area, this particular cartogram also represents the same data using five classes. This double representation affords different uses and interpretations of the thematic data and so increases its importance relative to locational information.
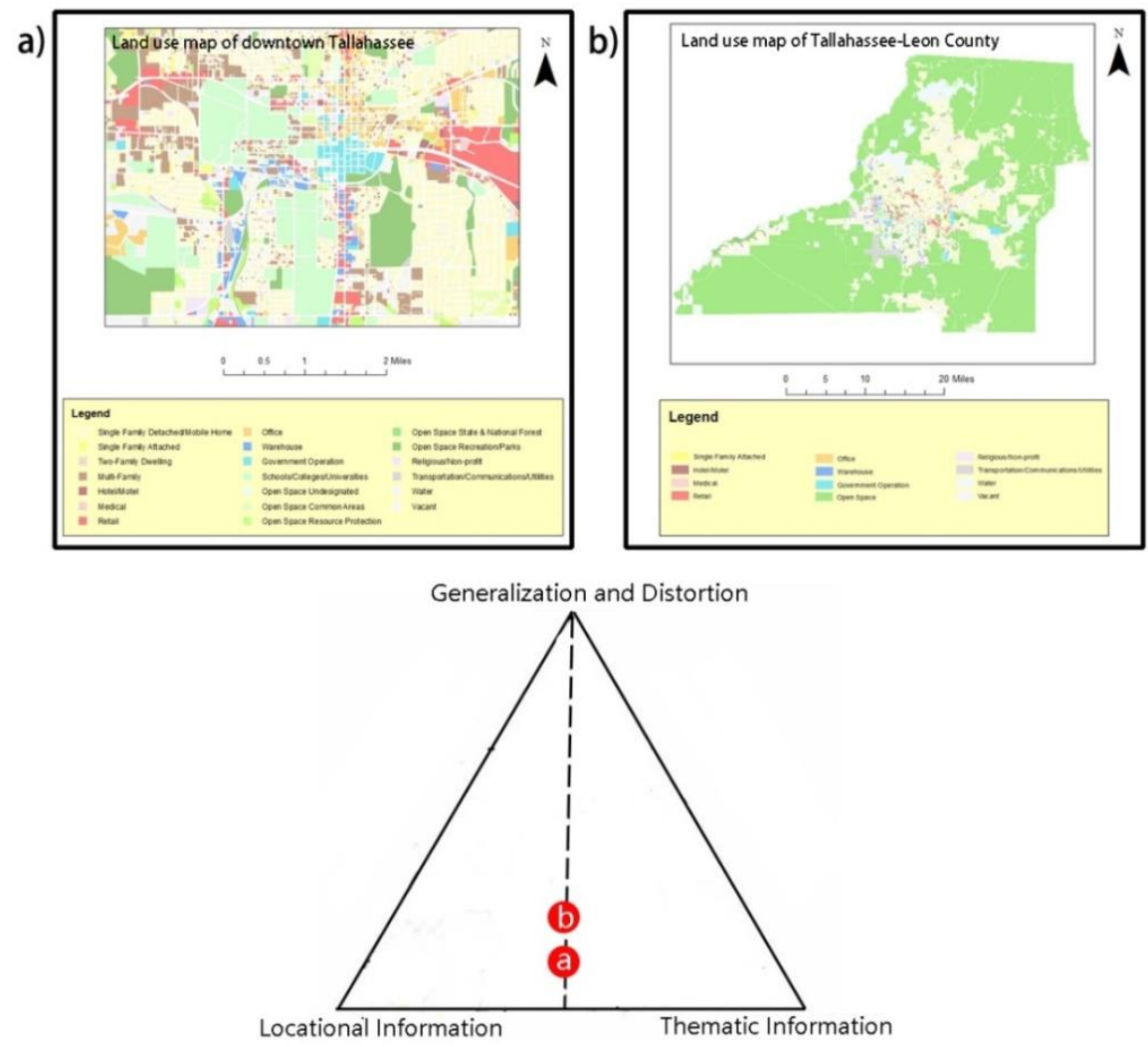

Figure 8. Examples of maps at different G-D levels in a medial-L/T position the map triangle: (a) Land use map of downtown Tallahassee; (b) Land use map of Tallahassee-Leon County. (Data source: Tallahassee County Planning Department. ${ }^{4}$ )

Maps located at a medial position in the L/T spectrum (Fig. 8) represent situations where the communication of locational and thematic data is more equally weighted. An example would be a land use map, in which the location information (location and geometry of land parcels) and thematic attribute information (land use types) are both potentially important. Figure 8a is a land use

${ }^{4}$ Accessed from: http://www.talgov.com/place/pln-stats.aspx (Oct. 2017). 
map of downtown Tallahassee, and Figure $8 \mathrm{~b}$ is a land use map of TallahasseeLeon County. Relative to the city-scale map, the county-scale map has geographic boundaries that are more generalized and distorted; additionally, the land use data are generalized into fewer categories. As a consequence, the county-scale map is placed at a higher G-D level.

Note that we have placed these two maps directly on the same iso-ratio line of locational to thematic information. This placement reflects the fact that, regardless of scale, the relative importance of the locational and thematic information is likely to be more determined by the immediate (and changing) user-defined uses of the maps rather than the inherent design characteristics of the maps themselves. In this regard, recall our earlier discussion of map purpose as an interplay between the intent of the mapmaker and the use and interpretation of the map by the map user. The positioning of maps along the medial line of the L/T cross-triangle spectrum should therefore be interpreted as a "pivot zone" wherein actual usage of the map sways the map to either the locational or the thematic side. This greater focus on the users and usage contrasts somewhat with the maps discussed previously, where the content itself (locational or thematic) more clearly impacts the purposes and interpretation for users.

a)
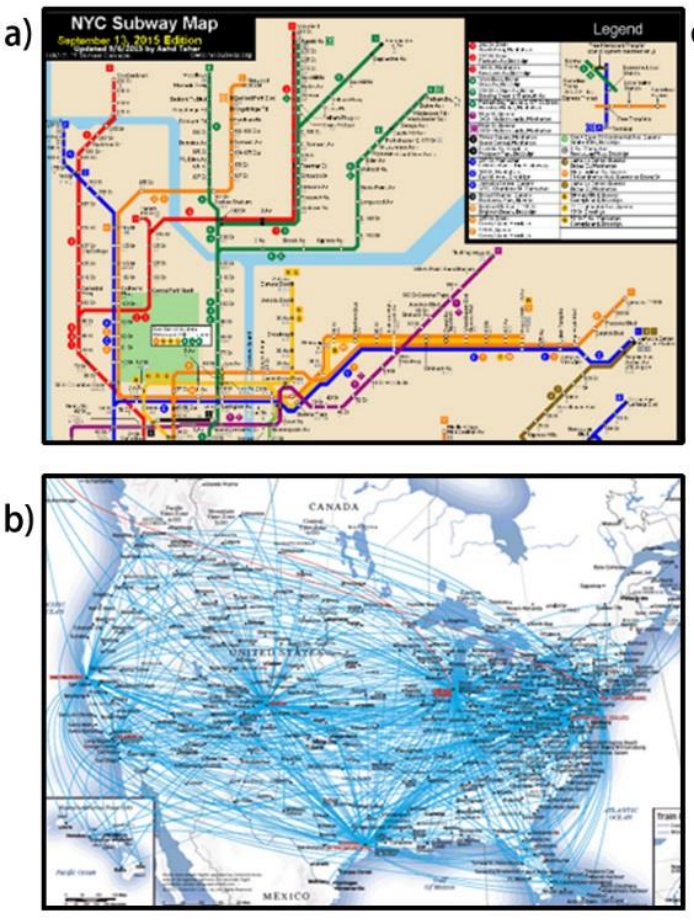

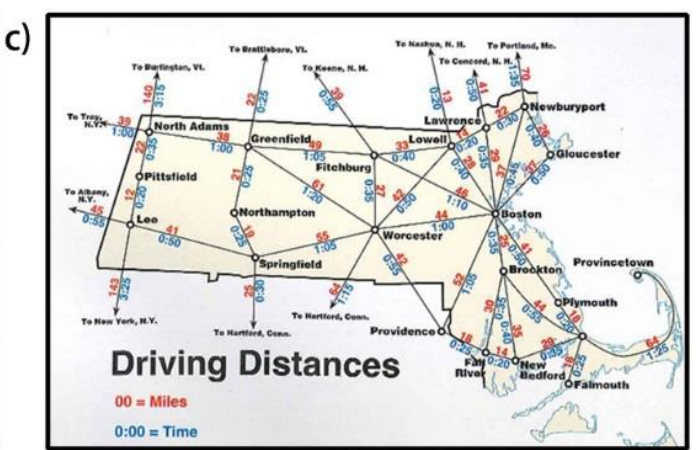

Generalization and Distortion

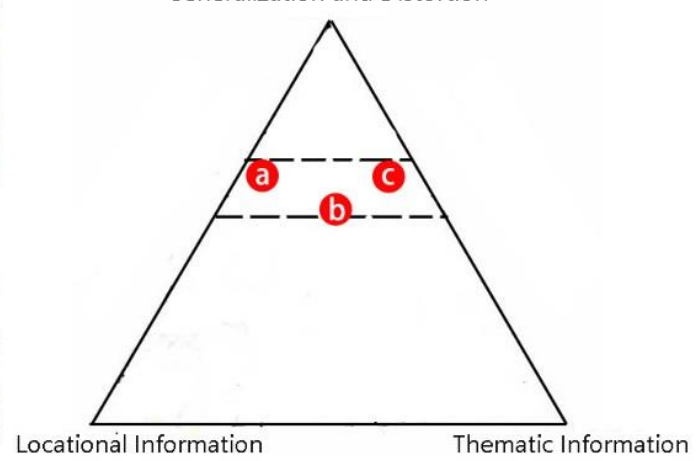

Figure 9. Examples of maps across a G-D band of the triangle: (a) Subway map of New York City (Calcagno 2010); (b) Route Map of United Airlines (United Airlines 2017); (c) Driving distances/time map for Massachusetts (Massachusetts Office of Travel and Tourism 2016). 
Figure 9 shows a cross-L/T band for maps of a similar G-D level. The subway map (Fig. 9a), although highly distorted geographically, remains a predominantly navigational (locational) tool, albeit one that relies on the topology of features (the connectivity of stations/lines) rather than their geometric properties of absolute location. The airline route map (Fig. 9b) is similarly, though relatively less, distorted; it is not a navigational tool but, rather, a means to convey the thematic information of flights between cities. To be sure, there is the implication of "connections," particularly if "hub" cities are identified, but the central purpose of the map is not for someone to be able to plan a navigable route across country, in the same way a subway map user does to cross a city. The purpose of the driving-time map (Fig. 9c), on the other hand, is to convey the thematic information of "driving time." The map is perhaps more generalized than distorted, and the locational generalization takes the form of the cities chosen for inclusion and the thematic generalization is the fact that times will be approximate and not reflective of different driving conditions (e.g., time of day, traffic, weather).

Seemingly similar maps may well be placed in different locations on the triangular plot, based on their own characteristics and purpose. For example, the barometric map in Figure 10a is an isopleth map of air pressure, with its location information in the form of contours; it provides rich locational information about differential high- and low-pressure extrema, pressure gradients, and wind speeds.

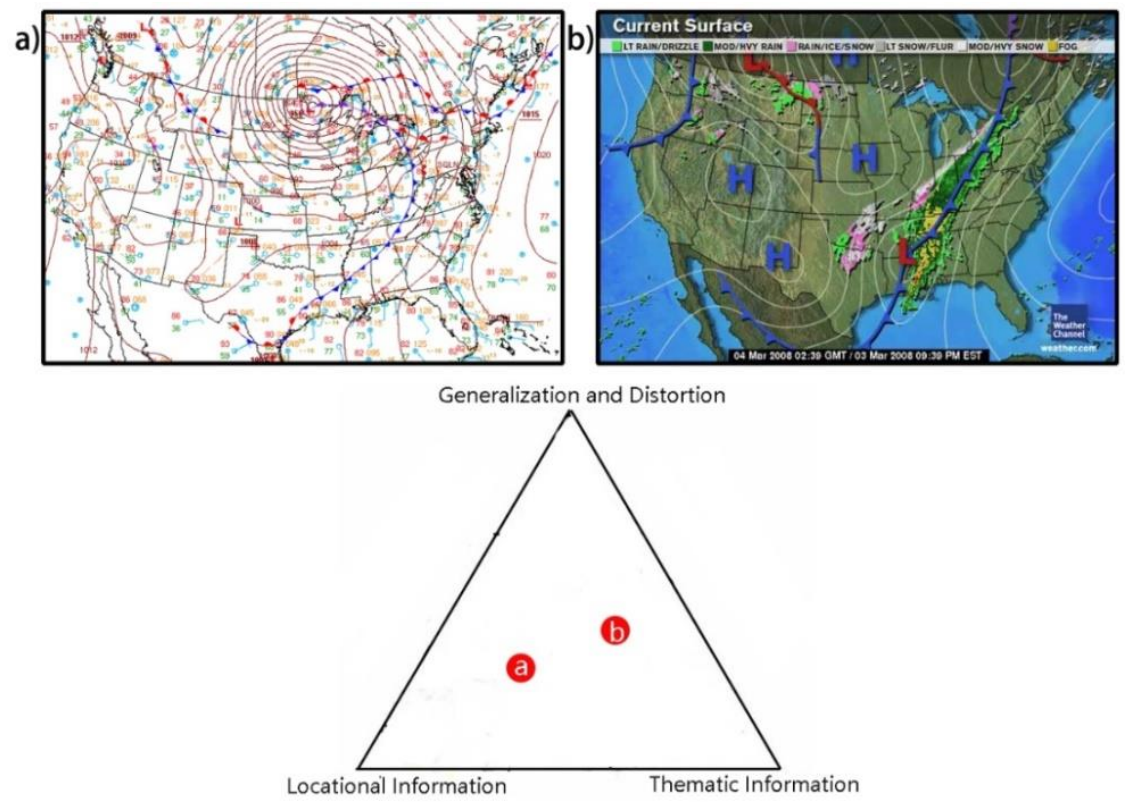

Figure 10. Examples of topically similar maps differing in both L/T and G-T: (a) Barometric map of United States (HPC Surface Analysis 2010); (b) Weather map of United States (The Weather Channel 2008). 
Meanwhile, the weather map in Figure $10 \mathrm{~b}$ has generalized the barometric contours through selection and/or re-categorization; has generalized the pressure extrema into symbolic labels ("H" and "L"); has highlighted the fronts; and has added precipitation data. These differences shift this map to the right of (smaller $\mathrm{L} / \mathrm{T}$ ) and above (higher G-D) the barometric map.

We contend that all maps can be located on the triangular plot based on the two parameters we have identified (viz., three conceptual endmembers but fundamentally two dimensions). To further evidence our contention, we can take a somewhat "three-corners approach" and consider three fairly extreme examples (Fig. 11). Figure 11a shows a "cartoon map" of theme parks near Orlando FL. The
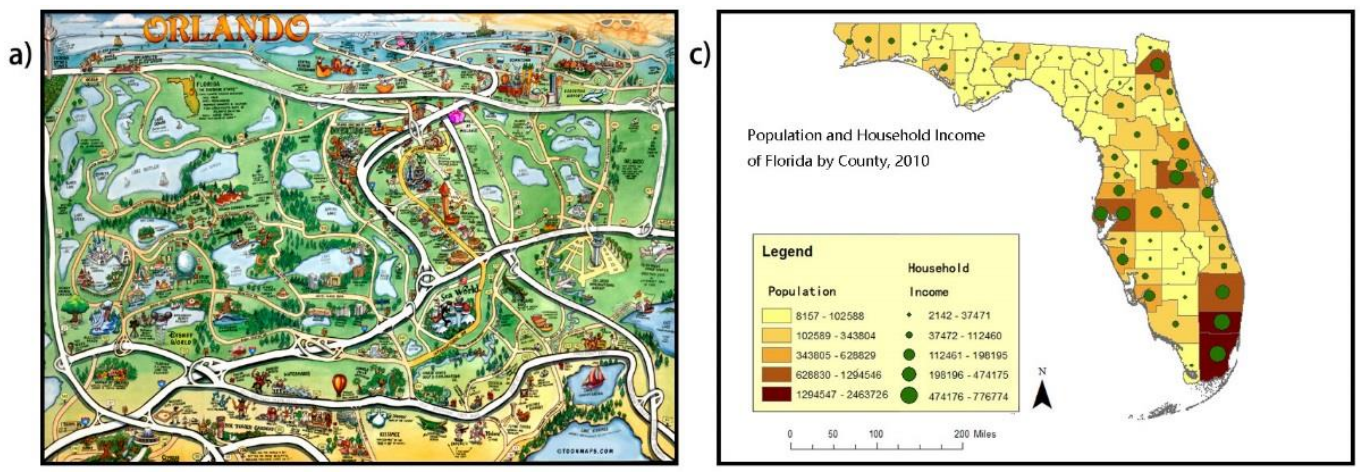

b)
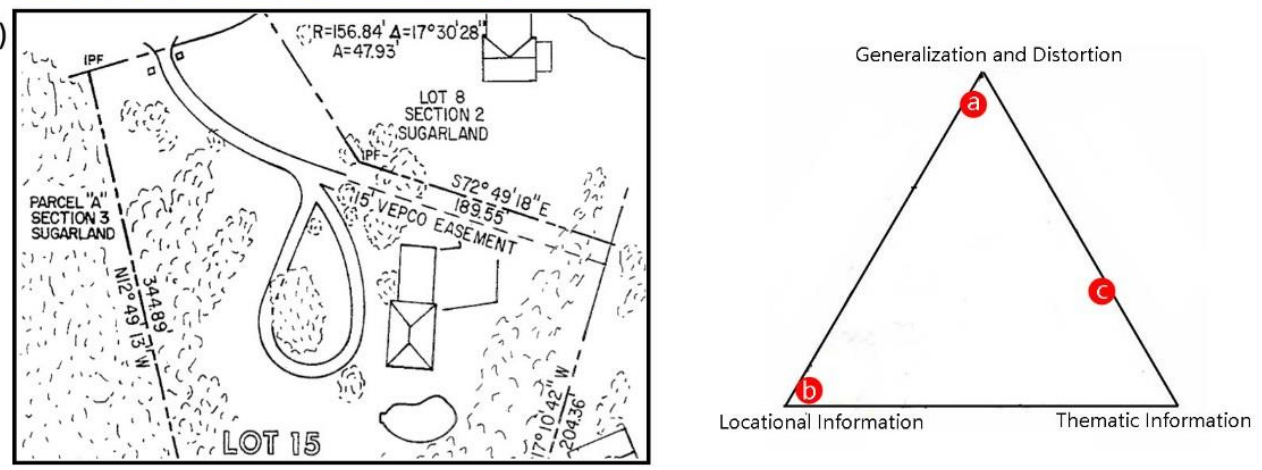

Figure 11. Examples of maps near the corners of the map triangle: (a) Cartoon map of city of Orlando (Middleton 2010); (b) Survey plot map (Veatch, 1995); (c) Multi-variable map showing the population and household income of Florida by county. (Data source: United States Census Bureau. $^{5}$

map's purpose is largely locational (i.e., navigational), showing approximate theme park locations and the major routes around them. The locational information is greatly generalized and/or distorted in this map and so it places to the upper left part of the triangular plot. In contrast, an engineering-survey plot (Fig. 11b) shows highly accurate and detailed locational information at a large scale. This type of map, therefore, locates at the lower left corner of the triangle.

${ }^{5}$ Accessed from: https://www.census.gov/mp/www/cat/decennial_census_2010/ 
Finally, a map communicating multiple thematic variables such as both countywide population and household income (Fig. 11c) is heavy on thematic information. The map locates firmly towards the right side of the triangle, and its vertical position depends very much on the degree of generalization-distortion in the thematic data representation.

\section{Discussion}

We argue that because maps vary so widely in their content, design, purpose, and scale of representation, a systematic framework for considering the features of maps that are most pertinent to quantitative map literacy is a necessary first step before we can discuss how and what quantitative concepts, skills, and facts are involved in quantitative map literacy. In the second paper of this series our focus will shift to that very discussion, but based on what we have reported here we can now provide a brief survey of the general landscape.

Our triangular plot framework emphasizes two parameters: the ratio of locational information to thematic information $(\mathrm{L} / \mathrm{T})$, and the level of generalization and/or distortion (G-D); the latter depends on the former to some extent. The $\mathrm{L} / \mathrm{T}$ ratio is fundamental for it divides the triangle into significantly different sides: a left side $(\mathrm{L} / \mathrm{T}>1)$, more aligned with data and experiences in STEM-type disciplines, continuous variables, and measurement; and a right side $(\mathrm{L} / \mathrm{T}<1)$, more aligned with data and experiences in social-science disciplines, categorical classifications, counting, and the need for statistical literacy (e.g., social construction of statistics) of the kind championed by Joel Best (2001, 2004, 2008) and Milo Schield (2004, 2010).

For maps with a high $\mathrm{L} / \mathrm{T}$ and of a scale where G-D is at a minimum for locational representation (i.e., lower part of the left side of the triangle), the quantitative knowledge and skills are more apt to be algebraic and of a routine nature familiar to lower-division STEM majors. Examples might include being able to use scale to calculate areas and distances, use ratios to calculate gradients, calculate angles for bearings and direction. Such calculations may be as precise as allowed for by the map or may be approximate (e.g., relative slopes) depending on the purpose. For maps with high L/T and at scales where G-D is relatively high (upper part of the left side), knowledge of the quantitative aspects of the methods of map projection and map generalization and how those aspects affect such calculations as those discussed above are all important. These questions are technically more advanced and often require a feeling for calculus to understand them (e.g., equal-area vs. equal-angle projections, rhumb lines, and the like).

For maps with a low $\mathrm{L} / \mathrm{T}$ ratio and of a scale where generalization and/or distortion are at a minimum for thematic representation (lower part of the right area), the quantitative concepts and skills are more likely to range across, as 
examples, comparison of quantitative thematic values, calculations of such comparisons, summarizing and assessing the spatial distribution of quantitative thematic values, and calculating thematic values relative to their geographic units. These topics in application are advanced, and they require more confidence and technical insight and sophistication than are typically attained in elementary statistics courses. Finally, for maps with a low L/T ratio and where thematic data representation is quite reductionist in nature (upper part of the right side), the quantitative concepts and skills are more apt to be descriptive-statistical and relatively low-order in nature (and thus more vulnerable for map users to be manipulated or misled). Examples might include knowledge of data classification methods, probability distributions, data transformations, and how these aspects affect the representation of the thematic data values. We would hope that students would be able to consider such topics with understanding as a result of their courses in elementary statistics (or, perhaps more specifically, statistical literacy).

The reader will note a certain dissymmetry in our discussion. Our current view is that the mathematical and statistical concepts, skills and facts needed for the lower part of the left side and the upper part of the right side of the triangle are ones that should draw upon relatively standard classroom training. Therefore, the "calculations" and "judgments" involved should be fairly familiar and of the kind that Polya (1957) characterized as "exercises." Meanwhile, the mathematical and statistical knowledge and skills involved in the upper part of the left side and lower part of the right side of the triangle may require mastery of a greater depth of concepts, skills, and facts as regards aspects such as map projection and generalization, evaluation and interpretation of the spatial distribution of thematic data, and in general more sophisticated interaction of calculation, analysis and context. These are what we believe Polya (1957) would have called "problems." In the medial zone midway between locational concentration and thematic concentration, the maps and the nature of the skills and knowledge are highly dependent on the specific questions the users are asking of them. The same map (a land-use map for example) could require high $\mathrm{L} / \mathrm{T}$-ratio thinking for some problems and low L/T-ratio thinking for other problems. Such is life in a transition zone.

The title of our paper claims that quantitative map literacy is a cross between map literacy and quantitative literacy. This is somewhat implicit in the discussion above but worth commenting on more directly. For maps which are more locational in nature, basic map literacy in terms of use of symbols is an inherent part of using quantitative knowledge and skills in the lower part of the left-side of the triangle, e.g. the calculation of slope based on the use of contours. For maps which are locational in nature but more generalized/distorted (upper part of the left side of the triangle) more advanced map literacy, in the form of knowledge of map projections and map generalization, is required to successfully apply 
quantitative knowledge and skills. On the thematic side, and particularly in the upper part of the right side of the triangle, there is perhaps less immediate dependency between map literacy and quantitative literacy, and the latter, often involving statistical literacy, tends to dominate. However, in the lower part of the right side of the triangle, we would argue that the required map literacy, such as the knowledge of how cartograms are created/read or the interpretation of spatial patterns and distributions, is quite high level and also fundamental to the successful application of quantitative knowledge and skills. In this regard, thematic maps, in particular, may also be good analogs of what Oughton (2018) refers to as "situated numeracy" where, in this case, the mapmaker's intent to convey a thematic message stimulates the application of QL knowledge and skills in the user.

\section{Conclusion}

We embarked on our exploration of quantitative map literacy (QML) because we believe that it has potential to stand alongside financial literacy (e.g., Gilliland et al. 2011; Lusardi 2012; de Bassa Scheresberg 2013; Lusardi and Wallace 2013; Nye and Hillyard 2013; Dahmen and Rodriguez 2014) and health numeracy (e.g., Baker et al. 1999; Lipkus et al. 2001; Vacher and Chavez 2009; Ancker and Begg 2017; Taylor and Byrne-Davis 2016, 2017) as an intrinsically interesting learning area for students who are in an environment supportive of QL across the curriculum (e.g., Steele and Kiliç -Bahi 2008; Forgasz et al. 2017). Our first step has been to try to get a handle on the wide diversity of maps that students may encounter. We have adopted a triangular approach to explicate map differences we think are critical to QL - mixing three endmembers (locational information, thematic information, and generalization and/or distortion) to define two parameters (L/T ratio and G-D level). We have used our proposed system to categorize a wide variety of maps (e.g., topographic maps, weather maps, engineering-survey plots, subway maps, maps of air routes, a cartoon map of Orlando, driving-time maps, county-wise population maps, county-wise multivariable population and income maps, world political map, land use maps, and cartograms). That exercise has given us a framework to explore the nature of QL in quantitative map literacy and how it depends on different types of maps. At this point we see this framework as one for faculty and educators to consider rather than one which might be presented as a QML "roadmap" for students and/or mapmakers, though this could later be the case, following further development, in designing a curriculum for QML. In part 2 of this series of papers, we will report on our own further exploration of QML using this framework. 


\section{Acknowledgments}

We thank Jason Boczar and LeEtta Schmidt of the University of South Florida Tampa Library for their help in getting copyright permission for the maps cited in this paper, and we thank the map makers for their permission to redistribute their work. We greatly appreciate the five reviewers of the original manuscript for the care and insight of their reviews. Their thoughtful criticisms led us to think more deeply and communicate more carefully about this challenging project.

\section{References}

Ancker, J. S., and M. D. Begg. 2017. "Using Visual Analogies to Teach Introductory Statistical Concepts." Numeracy 10 (2): Article 7. https://doi.org/10.5038/1936-4660.10.2.7

Baker, D. W., M. V. Williams, R. M. Parker, J. A. Gazmararian, and J. Nurss. 1999. "Development of a Brief Test to Measure Functional Health Literacy." Patient Education and Counseling 38 (1): 33-42. https://doi.org/10.1016/S0738-3991(98)00116-5

Best, Joel. 2001. Damned Lies and Statistics: Untangling Numbers from the Media, Politicians, and Activists. Berkeley CA: University of California Press.

- 2004. More Damned Lies and Statistics: How Numbers Confuse Public Issues. Berkeley CA: University of California Press.

—. 2008. "Birds-Dead and Deadly: Why Numeracy Needs to Address Social Construction." Numeracy 1 (1): Article 6. https://doi.org/10.5038/1936-4660.1.1.6

Bayran, S. and R. Ibrahim. 2005. "Digital Map Literacy Bounded with Culture Under Geographical Information Systems Perspective." Journal of Visual Literacy 25 (2): 167-176.

Board, C. 1978. "Map Reading Tasks Appropriate in Experimental Studies in Cartographic Communication." Cartographica: The International Journal for Geographic Information and Geovisualization 15 (1): 1-12.

Calcagno, M. 2010 New York City Subway Map, June 28, 2010 Edition.. http://www.nycsubway.org/perl/caption.pl?/img/maps/calcagno-2010-0628c.gif (accessed October 3, 2016).

Campbell, J. 1993. Map Use \& Analysis, 3rd Edition. Madison WI: WCP/McGraw Hill.

Clarke, D. 2003. “Are You Functionally Map Literate?” In Cartographic Renaissance, Proceedings of 21st International Cartographic Conference (ICC), Durban, South Africa: International Cartographic Association (ICA), 713-719. http://lazarus.elte.hu/cet/publications/088.pdf 
Dahmen, P., and E. Rodríguez. 2014. "Financial Literacy and the Success of Small Businesses: An Observation from a Small Business Development Center." Numeracy 7 (1): Article 3. https://doi.org/10.5038/1936-4660.7.1.3 de Bassa Scheresberg, C. 2013. "Financial Literacy and Financial Behavior among Young Adults: Evidence and Implications." Numeracy 6 (2): Article 5. https://doi.org/10.5038/1936-4660.6.2.5

Dent, B. D., J. S. Torguson, and T. W. Hodler. 2009. Cartography: Thematic Map Design, 6th Edition. Madison WI: McGraw Hill.

Derringh, E. 1998. Computational Engineering Geology. Upper Saddle River NJ: Prentice Hall.

Folk, R. L. 1974. The Petrology of Sedimentary Rocks. Austin TX: Hemphill Publishing Co.

Forgasz, H. J., G. Leder, and J. Hall, J. 2017. "Numeracy across the Curriculum in Australian Schools: Teacher Education Students' and Practicing Teachers' Views and Understandings of Numeracy." Numeracy 10 (2): Article 2. https://doi.org/10.5038/1936-4660.10.2.2

Gilliland, D., V. Melfi, A. Sikorskii, E. Corcoran, and E. Melfi. 2011. "Quantitative Literacy at Michigan State University, 2: Connection to Financial Literacy." Numeracy 4 (2): Article 6. https://doi.org/10.5038/1936$\underline{4660.4 .2 .6}$

Harvey, F. 2008. A Primer of GIS: Fundamental Geographic and Cartographic Concepts. New York: Guilford Press.

HPC Surface Analysis. 2010. Surface Barometric Map. http://capitalclimate.blogspot.com/2010_10_24_archive.html (accessed Augest 27, 2017).

Jenson, J.R., and R. R. Jensen. 2013. Introductory Geographic Information Systems. Boston MA: Pearson Education, Inc.

Jungck, J. R. 2012. "Incorporating Quantitative Reasoning in Common Core Courses: Mathematics for the Ghost Map." Numeracy 5 (1): Article 7. https://doi.org/10.5038/1936-4660.5.1.7

Koç, H. and S. B. Demìr. 2014. "Developing Valid and Reliable Map Literacy Scale." Review of International Geographical Education Online 4 (2): 120-137.

Kulhavy, R. W., D. R. Pridemore, and W. A. Stock. 1992. "Cartographic Experience and Thinking aloud about Thematic Maps." Cartographica 29 (1): 1-9.

Lee, J. and R. Bednarz. 2012. "Components of Spatial Thinking: Evidence from a Spatial Thinking Ability Test.” Journal of Geography 111 (1): 15-26. Lipkus, I. M., G. Samsa, and B. K. Rimer. 2001. "General Performance on a Numeracy Scale among Highly Educated Samples.” Medical Decision Making 21 (1): 37-44. https://doi.org/10.1177/0272989X0102100105 
Lloyd, R. E. and R. L. Bunch R. L. 2005. "Individual Differences in Map Reading Spatial Abilities Using Perceptual and Memory Processes." Cartography and Geographic Information Science 32 (1): 33-46.

_. 2008. "Explaining Map-Reading Performance Efficiency: Gender, Memory, and Geographic Information." Cartography and Geographic Information Science 35 (3): 170-202.

Lusardi, A. 2012. "Numeracy, Financial Literacy, and Financial DecisionMaking." Numeracy 5 (1): Article 2. https://doi.org/10.5038/1936-4660.5.1.2

— and D. Wallace. 2013. "Financial Literacy and Quantitative Reasoning in the High School and College Classroom." Numeracy 6 (2): Article 1. https://doi.org/10.5038/1936-4660.6.2.1

Massachusetts Office of Travel and Tourism. 2016. City to City Mileage and Drive Time.. https://www.massvacation.com/wpcontent/uploads/2015/03/city-to-city-driving-distances-1.jpg (accessed Aug 27, 2017).

Middleton, K., 2010. Toon Map of Orlando. http://www.fungraphix.com/toonmaps/OrlandoMap.html (accessed October 3, 2016).

Monmonier, M. 1996. How to Lie with Maps, 2nd edition. Chicago: University of Chicago Press.

Morrison, J. L., 1978, "Towards a Functional Definition of the Science of Cartography with Emphasis on Map Reading." The American Cartographer 5 (2): 97-110.

Nye, P., and C. Hillyard. 2013. "Personal Financial Behavior: The Influence of Quantitative Literacy and Material Values." Numeracy 6 (1): Article 3. https://doi.org/10.5038/1936-4660.6.1.3

Olson, J. M. 1976. "A Coordinated Approach to Map Communication Improvement." The American Cartographer 3 (2): 151-159.

Oughton, H. 2018. "Disrupting Dominant Discourses: A (Re)Introduction to Social Practice Theories of Adult Numeracy." Numeracy 11 (1): Article 2. https://doi.org/10.5038/1936-4660.11.1.2

Perez, V. W., J. Best, and R. J. Bacon. 2015. "Cancer Clusters in Delaware: How One Newspaper Turned Official Statistics into News." Numeracy 8 (1):

Article 7. https://doi.org/10.5038/1936-4660.8.1.7

Pettijohn, F. J. 1957. Sedimentary Rocks, 2nd edition. New York NY: Harper \& Brothers.

Pólya, George. 1957. How to Solve It, 2nd edition. Garden City NY: Doubleday. Poppe, L. J., K. Y. McMullen, S. J. Williams, and V. F. Paskevich, (eds.). 2014. USGS East-Coast Sediment Analysis: Procedures, Database, and GIS Data (ver. 3.0). U. S. Geological Survey Open-File Report 2005-1001. http://pubs.usgs.gov/of/2005/1001/. 
Rautenbach, V., S. Coetzee, and A. Coltekin. 2017. "Development and Evaluation of a Specialized Task Taxonomy for Spatial Planning - A Map Literacy Experiment with Topographic Maps." Journal of Photogrammetry and Remote Sensing 127: 16-26.

Rieger, M. 1999. “An Analysis of Map Users' Understanding of GIS Images.” Geomatica 53(2): 25-137.

Robinson, A.H. 1975. "Map Design.” Proceedings of the International Symposium on Computer-Assisted Cartography, Auto-Carto II, ed. John C. Kavaliunas, 9-14. http://mapcontext.com/autocarto/proceedings/auto-carto2/pdf/map-design.pdf (accessed Nov 27, 2017)

, and B. B. Petchenik. 1975. "The Map as a Communication System." Cartographic Journal 12: 7-15.

—, and R. D. Sale. 1969. Elements of Cartography, 3rd Edition. New York NY: John Wiley \& Sons Inc.

Schield, M. 2004. "Information Literacy, Statistical Literacy and Data Literacy." International Association for Social Science Information Services and Technology (IASSIST) Quarterly. Summer/Fall: 6-11.

- 2010. "Assessing Statistical Literacy: TAKE CARE." In Assessment Methods in Statistical Education: An International Perspective, ed. P. Bidgood, N. Hunt, and F. Joliffe, Ch 11: 133-152. Chichester, West Sussex, UK: John Wiley \& Sons Ltd. Excerpts at www.statlit.org/pdf/2010SchieldExcerptsAssessingStatisticalLiteracy.pdf

Slocum, T. A., R. B. McMaster, F. C. Kessler, and H. H. Howard. 2009. Thematic Cartography and Geovisualization, 3rd Edition. Upper Saddle River NJ: Pearson Prentice Hall.

Ssolbergj. 2009. Blank Map of Europe.. https://commons.wikimedia.org/wiki/File:Blank_map_of_Europe_(polar_ster eographic_projection)_cropped.svg (accessed January 24, 2017).

Steele, B., and S. Kiliç-Bahi. 2008. "Quantitative Literacy across the Curriculum: A Case Study." Numeracy 1(2): Article 3. https://doi.org/10.5038/1936$\underline{4660.1 .2 .3}$

Taylor, A. A., and L. M. Byrne-Davis. 2016. "Clinician Numeracy: The Development of an Assessment Measure for Doctors." Numeracy 9 (1): Article 5. https://doi.org/10.5038/1936-4660.9.1.5

- 2017. "Clinician Numeracy: Use of the Medical Interpretation and Numeracy Test in Foundation Trainee Doctors." Numeracy 10 (2): Article 5. https://doi.org/10.5038/1936-4660.10.2.5

The Weather Channel. 2008. Weather map of United States. Map 2008. https://www.theawl.com/2011/10/how-to-read-this-mornings-weather-map/ (accessed August 27, 2017). 
Tufte, E. R. 1992. The Visual Display of Quantitative Information, Cheshire CT: Graphics Press.

- 2001, Envisioning Information, Cheshire CT: Graphics Press.

Vacher, H. L. 2005. "Computational Geology, 29: Quantitative Literacy: Spreadsheets, Range Charts and Triangular Plots." Journal of Geoscience Education 53 (3): 324-333. http://nagt.org/files/nagt/jge/columns/CG29v53n3p324.pdf. -, and T. Chavez. 2009. "Quantitative Literacy on the Web of Science, 2 Mining the Health Numeracy Literature for Assessment Items." Numeracy 2 (1): Article 5. https://doi.org/10.5038/1936-4660.2.1.5

Veatch, J.W. 1995. Method and Apparatus for Generating a Comprehensive Survey Map. Google Patent. https://www.google.com/patents/US5414462

United Airlines. 2017. United Airline Routes within USA and Canada. http://www.airlineroutemaps.com/maps/United_Airlines (accessed August 27, 2017).

United Nations. 2010. Map of the World. https://en.wikipedia.org/wiki/File:World.pdf (accessed January 24, 2017).

U. S. Geological Survey. 1958. Dragoon Quadrangle Arizona-Cochise CO. 15 Minute Series (Topographic). Denver CO: U. S. Geological Survey. From US Topo Download. https://viewer.nationalmap.gov/basic/?basemap=b1\&category=ustopo\&title= US\%20Topo\%20Download (accessed October 3, 2016).

- 1996. Steele Hills Quadrangle Arizona-Cochise CO. 7.5 Minute Series (Topographic). Denver CO: U. S. Geological Survey. From US Topo Download. https://viewer.nationalmap.gov/basic/?basemap=b1\&category=ustopo\&title= US\%20Topo\%20Download (accessed October 3, 2016).

Wainer, H. 1997. Visual Revelations: Graphical Tales of Fate and Deception from Napoleon Bonaparte to Ross Perot. New York: Copernicus. https://doi.org/10.1007/978-1-4612-2282-8 